\title{
Logo based Dipole Antenna for RFID applications
}

\author{
Varindra Kumar ${ }^{1}$ \\ ${ }^{1}$ Department of Engineering \\ University of Cambridge \\ Cambridge, UK
}

\begin{abstract}
Antenna plays an important role in communicating signals between device. With the recent advancement in the IoT and miniaturization of devices, the application of antenna have increased. Wearable electronics have often found device integrated with fabric, providing various electronics functionalities for energy harvesting, medical, defense and consumer electronics. The advantage of the wearable device is, being the part of the fabric it keeps the user connected to various surrounding devices with ease. A logo dipole antenna has been designed here at $865 \mathrm{MHz}$ for RFID applications. The antenna has been designed for its integration with various RFID chips. Various antenna parameters such as return loss, gain directivity, bandwidth and efficiency has been calculated and analyzed.
\end{abstract}

Index Terms-Antenna, Dipole, Patch, Logo, RFID

\section{INTRODUCTION}

Due to various RFID applications across textile industries, there has been an increase in demand for antenna design which can provide the nature and flexibility of cloth and yet providing the functionality as expected of an electronic system $[1-4]$. The RFID system works at $860-960 \mathrm{MHz}$ across the Europe and $865.5-867.5 \mathrm{MHz}$ across the UK, hence the designed antenna should provide the functionality within this range. At the same time, the antenna should be compact and small with its intended bandwidth and good directivity, gain and radiation efficiency. Various papers have presented antenna design for wearable electronics in the past [5]. However this paper talks about a dipole logo antenna based on NTU with its resonance frequency at $865 \mathrm{MHz}$ and have been designed using a fine layer of copper strip over a nonconductive fabric substrate, Cordura ${ }^{\circledR}$ and Polyamide spacer [1]. The antenna can be embroidered using an embroidery machine for its integration with clothing. Further the antenna itself can be encapsulated using some polymer material such as thermoplastic polyurethane in order to avoid external unknown or unaccounted effect for its electromagnetic properties. The bending effect of the antenna has also been shown here. The paper has been divided into various sections with Introduction, Design, modeling and simulation results, comparison of parameters, conclusion and finally acknowledgement.

\section{Design}

A logo dipole antenna has been shown in Fig. 1. As shown here, it has two arms, forming two dipoles. There is a range of non-conductive fabric materials available for its selection, ranging from Cordura ${ }^{\circledR}$, Polyamide spacer, Cotton, Polyester, Quartzel $^{\circledR}$, Fleece and Woolen felt fabric [1]. The fabric material Cordura $^{\circledR}$ and Polyamide spacer has been selected here as these substrate for the antenna design can provide a stable geometry, constant thickness, if it is elongated or shrunk and resistance for its intended work. Similarly there is a range of conductive material fabric for its design such as Copper foil, Flectron, Zelt, and certain composition of Silver, Copper and Nickel.

The antenna with thin copper conductor has been modelled over a thin layer of substrate with thickness of $0.5 \mathrm{~mm}$. The non-conducting textile substrate material Cordura $^{\circledR}$ with its relative permittivity $\left(\varepsilon_{\mathrm{r}}\right)$ of 1.90 and loss tangent of 0.0098 and Polyamide spacer with its relative permittivity $\left(\varepsilon_{\mathrm{r}}\right)$ of 1.14 and loss tangent of 0.00 has been used here [1]. The total dimension of the conductive patch has been calculated as $98 \mathrm{x}$ $134 \mathrm{~mm}^{2}$ while substrate has a dimension of $118 \times 154 \mathrm{~mm}^{2}$. The planar shape of the antenna has been shown in Fig. 2 while the bend shape has been illustrated in Fig. 3. As the intended application of the antenna on its bend as wearable electronics can change the electromagnetic property of the patch and substrate, causing the resonance frequency to shift and/or change its bandwidth and other parameters, the bend effect has also been shown here [6].

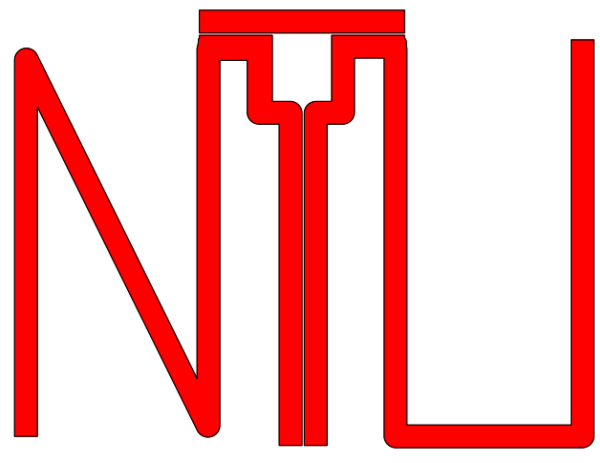

Fig. 1 Logo antenna

\section{Modelling And Simulation Results}

The CST software has been used to model and simulate the logo based dipole antenna. Section A describes the detail about the reflection coefficient for a patch antenna with copper conductive media for planar and bend structure while section 
B talks about the parametric results of the bend antenna for its bending effect with Cordura ${ }^{\circledR}$ fabric material.

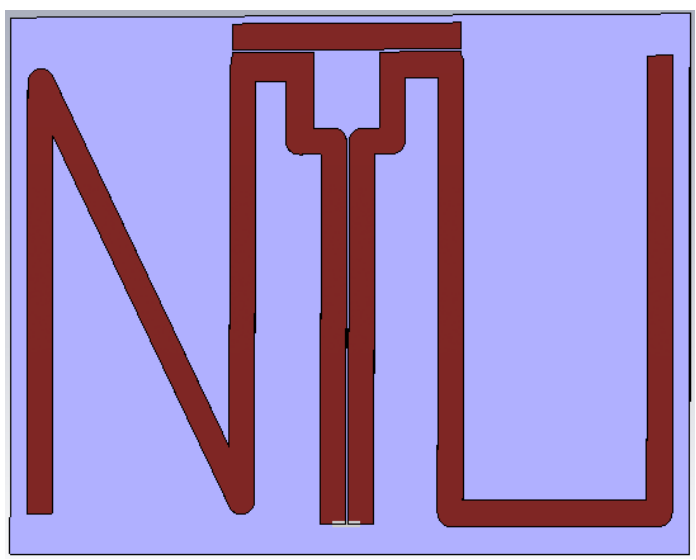

Fig. 2 Planar Dipole antenna

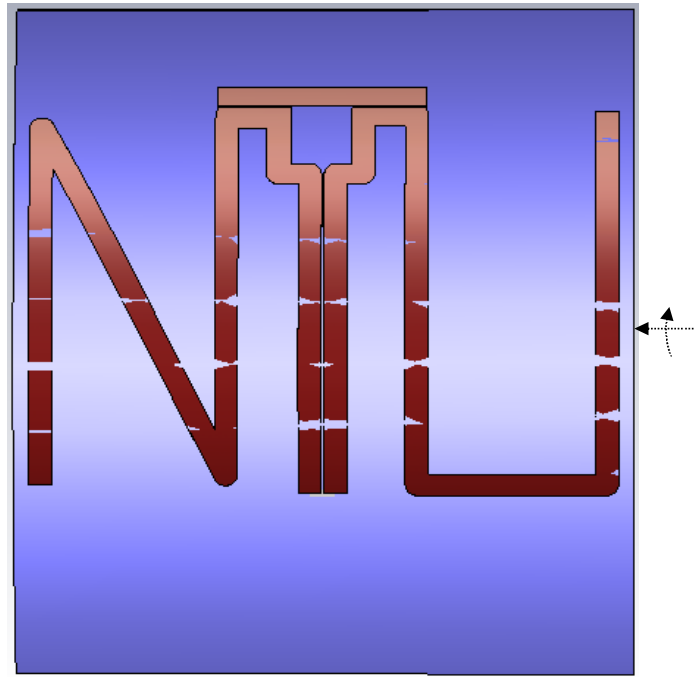

Fig. 3 Bend Dipole antenna (arrow indicates the bending direction)

\section{A. Patch Antenna using Copper Conductor}

Figs. 4 and 5 show the reflection coefficient of the dipole antenna over the plane and bend form using Cordura ${ }^{\circledR}$ and Polyamide spacer as its substrate. As seen from Fig. 4, these planar patches show its resonance behavior at $872.68 \mathrm{MHz}$ with $-10.60 \mathrm{~dB}$ reflection and $900 \mathrm{MHz}$ with $-9.49 \mathrm{~dB}$ reflection respectively. Similarly Fig. 5 shows the resonance behavior of the bend patch with its resonating frequency at 868.9 MHz with $-11.72 \mathrm{~dB}$ reflection for Cordura ${ }^{\circledR}$ and 895.52 $\mathrm{MHz}$ with $-10.42 \mathrm{~dB}$ reflection for Polyamide spacer substrate. As seen from Figs. 4 and 5, the reflection coefficient of a planar and bend structure compares quite well at its resonating frequencies and within the RFID frequency range of $860-960$ $\mathrm{MHz}$ for a small bend in the shape.



Fig. 4 S11 parameter for planar patch

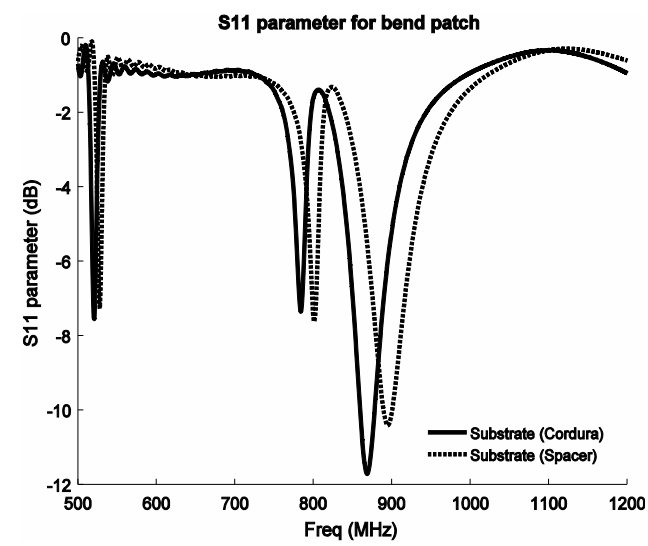

Fig. 5 S11 parameter for bend patch

\section{B. Patch Antenna using Copper Conductor}

Fig. 6 shows the variation of the reflection coefficient for its bending effect due to variation in bending radius. Here an antenna designed over Cordura ${ }^{\circledR}$ substrate has been used for the result.

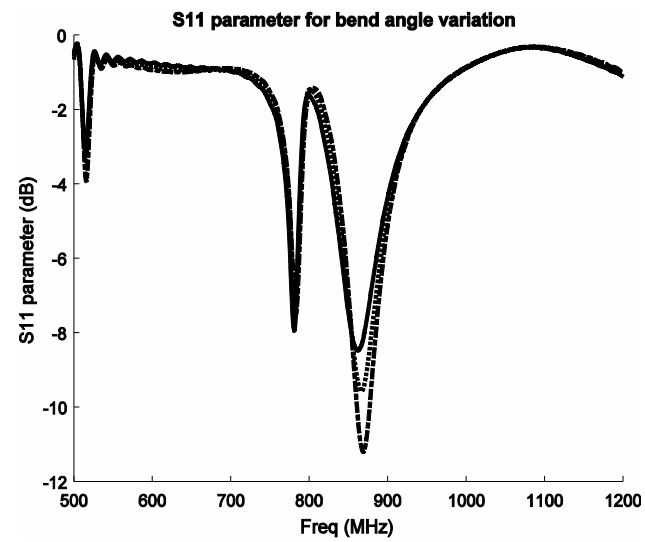

Fig. 6 S11 parametric variations for bend patch 


\section{COMPARISON OF PARAMETRS}

Table I shows the comparison of resonance frequency, reflection coefficient, VSWR and Gain at $\varnothing=90^{\circ}$ for planar and bend antenna with Cordura $^{\circledR}$ and Polyamide spacer substrate media while Table II shows the directivity, main lobe direction and total efficiency. As seen from these Tables, the bend structure provides higher gain and efficiency however the designed antenna structure can provide reasonable total efficiency and gain at its resonance.

TABLE I

COMPARISON OF PATCH ANTENNAS

\begin{tabular}{|c|c|c|c|c|c|}
\hline Substrate & Patch & $\begin{array}{c}\text { Freq }\left(\mathrm{f}_{\mathrm{o}}\right) \text { in } \\
\mathrm{MHz}\end{array}$ & S11 $(\mathrm{dB})$ & VSWR & Gain $(\mathrm{dB})$ \\
\hline Cordura $^{\mathbb{R}}$ & Planar & 872.68 & -10.60 & 1.837 & 4.77 \\
\cline { 2 - 6 } & Bend & 868.9 & -11.72 & 1.70 & 4.83 \\
\hline $\begin{array}{c}\text { Polyamide } \\
\text { spacer }\end{array}$ & Planar & 900.0 & -9.49 & 2.00 & 4.55 \\
\cline { 2 - 6 } & Bend & 895.52 & -10.40 & 1.86 & 4.71 \\
\hline
\end{tabular}

TABLE II

COMPARISON OF PATCH ANTENNAS CONTD.

\begin{tabular}{|c|c|c|c|c|c|}
\hline & & $\begin{array}{c}\text { Freq }\left(\mathrm{f}_{\mathrm{o}}\right) \text { in } \\
\mathrm{MHz}\end{array}$ & $\begin{array}{c}\text { Directivity } \\
(\mathrm{dBi})\end{array}$ & $\begin{array}{c}\text { Main Lobe } \\
\text { direction }\left({ }^{\circ}\right)\end{array}$ & $\begin{array}{c}\text { Total } \\
\text { Efficiency (\%) }\end{array}$ \\
\hline \multirow{2}{*}{ Cordura $^{\circledR}$} & Planar & 872.68 & 4.93 & 90.0 & 92.75 \\
\cline { 2 - 6 } & Bend & 868.9 & 4.99 & 115.0 & 94.50 \\
\hline $\begin{array}{c}\text { Polyamide } \\
\text { spacer }\end{array}$ & Planar & 900.0 & 4.55 & 90.0 & 78.46 \\
\cline { 2 - 6 } & Bend & 895.52 & 4.72 & 119.0 & 81.92 \\
\hline
\end{tabular}

\section{References}

[1] R. Salvado, C. Loss, R. Gonçalves, and P. Pinho, Textile materials for the design of wearable antennas: a survey, Sensors (Basel)., vol. 12, no. 11, pp. 15841-57, Jan. 2012.

[2] G. Monti, L. Corchia, and L. Tarricone, UHF wearable rectenna on textilematerials, IEEE Transactions on Antennas and Propagation, vol. 61, no. 7, pp. 3869-3873, 2013.

[3] M. A. Ziai and J. C. Batchelor, UHF RFID tag antenna design for on-Body applications, Antennas \& Propagation Conference, Loughborough, UK, pp. 185-188, 8-9 November 2010.

[4] H. R. Sanjari, A. A. Merati, S. M. H. Varkiani and A. Tavakoli, A study on the effect of compressive strain on the resonance frequency of rectangular textile patch antenna: elastic and isotropic model, The Journal of The Textile Institute, vol. 105, no. 2, pp. 156-162, 2014.

[5] M. R. Islam and M. Ali, A novel wearable antenna array for $2.45 \mathrm{GHz}$ WLAN application, IEEE International Symposium on Antennas and Propagation, pp. 2754-2757, 2011.

[6] P. Salonen, Y. Rahmat-samii, M. Schaffrath and M. Kivikoski, Effect of Textile Materials on Wearable Antenna Performance: A Case Study of GPS

\section{CONCLUSION}

The modeling and simulation result of a dipole logo antenna for RFID applications has been shown here and various antenna parameters has been investigated for Cordura ${ }^{\circledR}$ and Polyamide spacer as its substrate media with planar and bend shape.

As seen from their various simulation results, the designed dipole antenna provides an excellent gain and directivity with good efficiency at $865 \mathrm{MHz}$. However the antenna can also work as a wide band antenna within its RFID frequency range of $860-960 \mathrm{MHz}$. The designed antenna being made of very thin conducting and substrate material, can provide mechanical flexibility while still maintaining the electronics functionality. This makes the design quite suitable for wearable electronics applications apart from many other automotive, medical and energy harvesting applications.

\section{Acknowledgement}

The author would like to acknowledge the CSIC at Department of Engineering, University of Cambridge for providing the necessary support and funding for the project. This project was completed as part of the supervision to UROP projects.

Antenna, Proceedings of IEEE Antennas and Propagation Society International Symposium, Monterey, CA, USA, pp. 459-462, 20-25 June 2004.

[6] K. V. Tumsare and P. L. Zade, Dual band logo antenna for WLAN application, 2016 World Conference on Futuristic Trends in Research and Innovation for Social Welfare (Startup Conclave), Coimbatore, pp. 1-4, 2016.

[7] C. A. Balanis, Antenna theory: analysis and design (3rd ed.), John Wiley \& Sons, New Jersey, USA, 2005.

[8] M. Stoppa and A. Chiolerio, Wearable Electronics and Smart Textiles: A Critical Review. Sensors, vol. 14, pp. 11957-11992, July 2014.

[9] Y. Y. Lu, S. C. Wei, C. Y. Li and H. C. Huang, Design of $2.45 \mathrm{GHz}$ Planar Meander Dipole Antenna, 2011 Seventh International Conference on Intelligent Information Hiding and Multimedia Signal Processing, Dalian, pp. $5-8,2011$.

[10] K. L. Jorgensen and K. B. Jakobsen, Logo antenna for $5.8 \mathrm{GHz}$ wireless communications, 2016 International Workshop on Antenna Technology (iWAT), Cocoa Beach, FL, pp. 165-166, 2016. 